\title{
Um olhar transversal para as danças do mundo
}

SOARES, Andréa Moraes ${ }^{1}$.

DANTAS, Mônica Fagundes².

\section{Resumo}

Este artigo propõe uma reflexão sobre a transversalidade como um novo olhar para a dança atual, a partir da perspectiva pós-colonialista, que pressupõe que todas as danças são igualmente potentes artisticamente. Apresenta como exemplo o espetáculo "Puz/zle" do amplamente reconhecido coreógrafo Sidi Larbi Cherkaoui, que utiliza-se desta temática em sua concepção, para então abordar a experiência de composição da coreografia "El Charque", uma hibridização de dança do ventre e dança contemporânea a partir da assimilação da poética de Eva Schul.

Palavras-chave: Pós-Colonialismo - Hibridação

- Dança do Ventre

\begin{abstract}
This paper proposes a reflection on the "transversality" as a new glance at the contemporary dance, from the post-colonial perspective, which assumes that all dances are equally potent artistically. It presents as an exemple the show "Puz/zle" by the widely recognized choreographer Sidi Larbi Cherkaoui, which uses up this theme in their design. It also addresses the choreographic composition "El Charque" which hybridizes belly dance and contemporary dance from the assimilation of Eva Schul poetics.
\end{abstract}

Keywords: Post-Colonial - Hybridization - Belly Dance
1.

Bailarina e coreógrafa

de dança do ventre, Graduada em Comunicação, Especialização em Dança e Mestre em Artes Cênicas - UFRGS. E-mail:

deadasofi@gmail.com

2.

Doutorado pela Universidade do Québec em Montreal (Canadá) 2008. Professora do Programa de Pós Graduação da UFRGS. E-mail: modantas67@gmail.com 
Introdução

Propomos para o tema "transversalidade", abordar um outro olhar para a dança no mundo atual. Neste sentido, propomos a transversalidade como um olhar sobre um ponto de vista não usual: aquele que não é nem o que está entre os seus como um igual, nem o que está entre os outros como o diferente. Ele é o estrangeiro, está "entre" um lado e outro, com um duplo pertencimento que não lhe confere uma posição comum.

Pode-se pensar na eventualidade deste olhar depararse com algo que para ele seja novo e então, há o primeiro momento de estranhamento, "o choque". No choque há uma provocação irresistível de buscar nomear, resumir, estabelecer comparações e entendimentos, mas estas conexões não parecem óbvias ao indivíduo, não são de seu conhecimento. No "choque", este encontro inominável acontece como um arrebatamento, repulsa ou com uma certa dose de temor. Sensações que o indivíduo vivencia e que dificilmente consegue afastar seu olhar do que busca decifrar. Neste ponto a análise realiza-se, na maioria das vezes, em uma estrutura binária: é arte, não é arte, é bom, não é bom. Pertencer a uma posição "liminar" facilita a análise sob uma perspectiva diferente que pode ampliar nossa compreensão sobre a dança enquanto arte. Falamos da perspectiva pós-colonialista e seu olhar transversal para a dança não ocidental.

Neste artigo explanamos sobre a visão pós-colonialista e sua contribuição para a dança, apresentando um exemplo amplamente reconhecido no mercado internacional para então abordar a experiência de composição de uma coreografia que hibridiza a dança do ventre e a dança contemporânea.

Um outro olhar para a dança:

o pós-colonialismo como transversalidade

A perspectiva pós-colonialista para a dança parte de um outro lugar: o abismo, a fronteira, o local, o entre-lugar, sem um pertencimento único mas capaz de olhar e ser parte de múltiplos mundos. Homi Bhabha explica que a perspectiva póscolonial surge do

[...] testemunho colonial dos países do Terceiro Mundo e dos discursos das "minorias" dentro das divisões geopolíticas de leste e Oeste, Norte e Sul. Elas intervêm naqueles discursos ideológicos da modernidade que tentam dar uma "normalidade" hegemônica ao desenvolvimento irregular e às histórias diferenciadas de nações, raças, comunidades, povos. Elas formulam suas revisões críticas em torno de questões de diferença cultural, autoridade social e discriminação política a fim de revelar os momentos antagônicos e ambivalentes no interior das "racionalizações" da modernidade (BHABHA, 2010, p.239). 
Por meio das teorias pós-coloniais pode-se compreender as culturas fora das oposições binárias de comparações entre o Ocidente e "os outros" pois "[...] é com aqueles que sofreram o sentenciamento da história - subjugação, dominação, diáspora, deslocamento - que aprendemos nossas lições mais duradouras de vida e pensamento." (BHABHA, 2010). É através destas pessoas e suas experiências que emerge, a "estratégia da cultura de sobrevivência" que, como um dos efeitos relacionados à desterritorialização, é transnacional e tradutória.

Segundo Roque Laraia (2001) "a cultura é como uma lente através do qual o ser humano vê o mundo" (p. 67). Através dela adquirimos padrões sociais de comportamento, valores morais e até posturas corporais. Desse modo, a cultura alimenta e é alimentada pela identidade, o que tende a fazer com que o indivíduo considere o seu modo de vida como o mais correto e natural, como uma lente que depura o que seria para ele "próprio" ou "impróprio".

Esta proposição pode explicar a tendência etnocêntrica com que pesquisadores ocidentais olham para danças não norte-americanas e não europeias (Curt Sachs, John Martin, Walter Terry entre outros) e as classificam como "exóticas", "primitivas", "étnicas" e "folclóricas" (apud SHAY; SELLERSYOUNG, 2005) enquanto as suas danças pertencem ao grupo minoritário da arte de elite.

Joan Kealinohomoku em seu artigo "An antropologist looks at ballet as a form of ethnic dance" (1970) incentiva-nos o cuidado ao utilizarmos estes termos sem correr o risco de considerá-los semelhantes. Da mesma forma, ela incentiva-nos o cuidado ao abordar danças que não são próximas à nossa cultura, evitando fazê-lo de forma superficial e até equivocada, por falta de conhecimento mais profundo no dado objeto de estudo.

Kealinohomoku (1970) promoveu um olhar crítico para a dança cênica ocidental, vista como arte culta por uma sociedade, que, ao mesmo tempo, vê as demais práticas como "ilegítimas" do mesmo status. A autora faz uso dos mesmos autores que classificam as danças étnicas depreciativamente, aplicando a mesma ideia para analisar o balé clássico, tido como arte culta, sinônimo da hegemonia burguesa e expressão da elite. Neste ousado movimento de autocrítica, Kealinohomoku nos mostra o quão étnico é o balé: um estilo que é produto do mundo ocidental, uma forma de dança desenvolvida por caucasianos que falam linguagens indo-europeias e que dividem tradições comuns. Segundo a autora, também o balé clássico é étnico e pode carregar o mesmo estranhamento e exotismo se interpretado em uma ilha javanesa, por exemplo. 
Se pensarmos em nossa cultura, veremos o quão híbrida ela é, mestiça em sua origem étnica por meio de matrizes indígenas, africanas, espanholas e portuguesas. Olhando para a cultura portuguesa e espanhola veremos a invasão árabe por 900 anos na península Ibérica. Manoelito de Ornellas (1999) conta em seu livro que o mouro teve forte influência na construção do Brasil colônia. A arquitetura moura, bem como as danças mouriscas, estiverem presentes na colônia durante a ocupação e catequização dos índios pelos colonizadores. Nossa cultura é híbrida e herdeira de hibridação por parte dos colonizadores.

Susan Foster em seu livro "Worlding Dance" (2009), questiona o uso das definições que utilizamos para classificar as danças, em geral as danças não ocidentais, que possam estigmatizá-las ou depreciá-las de alguma forma. Ela propõe, ao invés de "ethnic dance", o uso do termo "world dance", à exemplo da música, que faz uso de terminologia semelhante - "world music" - para músicas de origem não ocidental. Foster (2009) explica que as classificações hierarquizadas tem "eufemisticamente trabalhado para encobrir o legado colonial de hierarquizações raciais e classicista das artes" (p. 2) Para a autora, o termo "dança do mundo" sugere um campo neutro comparativo onde todas as danças são produtos de igual importância, maravilhosamente diversificada, equivalentemente poderosas culturalmente..

Assim, o estar na fronteira, sem definição estética delimitada, sem definição cultural fixa (nem dança brasileira, nem dança árabe) coloca-nos em um lugar privilegiado para um novo entendimento, um entendimento transversal. Surge um lugar pouco explorado: o interstício, aberto ao novo, sem as amarras rígidas da busca por autenticidade e tradição.

O olhar transversal do sujeito na liminaridade entende cada diferença como potência e vê na mistura entre culturas novas possibilidades de criação. Talvez por isso a arte contemporânea do ocidente tenha, cada vez mais, bebido na fonte do "primitivo", do "popular" do "étnico" e "folclórico" para renovar-se. Por outro lado, esta fonte convive, no ocidente, com um estereótipo estanque, imutável ao longo do tempo. Eles alimentam a arte ocidental contemporânea como inspiração exótica, mas não são considerados arte, e por isso não ocupam o mesmo nobre espaço ideológico que as práticas culturais ocidentais. Porém, alguns artistas tem descoberto o valor das práticas ditas "primitivas", "exóticas" se vistas como arte, vividas e exploradas no sentido experimental, a ponto de compreender seus contextos e revelar suas grandezas. Um destes artistas é o coreógrafo Sidi Larbi Cherkaoui. 


\section{Artista anfíbio}

Um exemplo de utilização de matrizes étnicas para a composição contemporânea é o espetáculo Puz/zle do coreógrafo Sidi Larbi Cherkaoui: o hibridismo como liberdade criadora, o orientalismo como potência e o virtuosismo como singularidade. Este inebriante espetáculo miscigenado em raças e tempos, jamais seria possível se não fosse o hibridismo. O hibridismo liberta. O tempo primitivo foi a inspiração, a modernidade esculpiu templos, túmulos, escadas e muros nas pedras de Puz/zle e nos corpos dos bailarinos.

Não obstante Nestor Garcia Canclini (2011) afirme que as vanguardas artísticas já tenham rompido todas as barreiras, os artistas contemporâneos buscam corrompê-las por meio da inovação. Cherkaoui não. Ele rompe a barreira hegemônica, a barreira do tempo, a barreira entre culturas, entre credos e raças. Corpos diferentes com movimentos diferentes confluem no mesmo espetáculo. O tempo do primitivo, o tempo do pop, o lento do butoh, o rápido do contemporâneo constroem Puz/ zle tornando-o uma experiência memorável.

Sentado na plateia do teatro Alfa, e arrebatado pela virtuosa confluência de ideias, sons e movimentos, Nestor Garcia Canclini certamente diria: - Cherkaoui, é um artista anfíbio! Para Canclini estes artistas

\footnotetext{
[...] são capazes de articular movimentos e códigos culturais de diferentes procedências. Como certos produtores teatrais, como grande parte dos músicos de rock, ele[s] mostram que é possível fundir as heranças culturais de uma sociedade, a reflexão crítica sobre seu sentido contemporâneo e os requisitos comunicacionais da difusão maciça. (CANCLINI, 2011, p. 350)
}

Em Puz/zle, percebe-se as diversas correntes culturais que inspiraram o artista em sua concepção: as ondulações da dança árabe, os movimentos de grupo da dança Pakarena da Indonésia, a dança de rua americana e seus grafites, o extremo oriente com a alusão ao Butoh, a música em diversas línguas: - italiana, libanesa, americana, francesa, músicas sacras e não sacras.

Talvez a genialidade do jovem coreógrafo sidi Larbi Cherkaoui seja também produto de sua origem liminar: "Desde cedo aprendi a ficar entre, porque nasci cristão e muçulmano. Precisei estudar filosofia para entender que não quero um mundo no qual alguém me diz o que é certo e errado e tampouco o que devo fazer" (CHERKAOUI, citado por KATZ, 2013). Não julgar o que é certo e errado, não julgar o melhor ou pior assoma-se em Puz/zle quando vemos a dança hip hop e seus grafites nos mesmos muros onde antes, enquanto escadarias, as pedras abrigavam os corpos em movimentos indianos, árabes e bali-hindus. 
Neste espetáculo não existe a hierarquia entre estilos e formas e sim um constante entre: entre estilos, entre culturas, entre corpos de diferentes nacionalidades, entre o tempo do primitivo e o tempo do moderno. Uma visão de mundo transversal, de quem precisou conviver com uma procedência ambígua sem escolher o lado certo e renegar o outro, como um anfíbio que vive tanto na água quanto na terra.

Cherkaoui nos ensina, tanto quando Kealinohomoku e Canclini, que o pertencimento a muitas culturas e a diferentes épocas se acentua no mundo atual e que somos todos, de uma forma ou de outra, híbridos. A hibridação utilizada por ele como liberdade criadora é uma visão de mundo generosa que multiplica suas possibilidades criadoras. Talvez isto explique sua capacidade de criar tantas obras em tão pouco tempo e com uma diversidade de estilos e formas tamanha: seu ser artista anfíbio.

Se por um lado a hibridação que se vê em Puz/zle dê ao espetáculo novas possibilidades de composição, há uma limitação de utilização desta hibridação na medida em que os corpos dos bailarinos não são transformados. Todos possuem técnicas diferentes que vão do pop ao Butoh, mas seus corpos não se contaminam com as propostas coreográficas pós-coloniais que o espetáculo Puz/zle propõe. As execuções são realizadas de forma que não seja necessário que os bailarinos tornem-se habilidosos em uma técnica nova. Como estamos abordando o olhar transversal para a dança não europeia ou norte-americana, o pós-colonialismo estaria melhor configurado, neste espectro, em uma apresentação contemporânea onde uma matriz de movimento não ocidental fosse utilizada como técnica corporal. Desta forma, propomos a análise da composição da coreografia "El Charque", que utilizou como matriz de movimento a dança do ventre para uma composição contemporânea.

\section{El Charque}

A coreografia El Charque foi desenvolvida como parte de um memorial de criação no âmbito do Programa de Pós Graduação em Artes Cênicas da Universidade Federal do Rio Grande do Sul. El Charque partiu do interesse de utilizarmos a técnica da dança do ventre como referência principal de uma criação em dança que não estivesse subordinada aos cânones da composição clássica tradicional em dança do ventre. Para isso, o entendimento da hibridação enquanto pressuposto para a não limitação de uma criação pré-concebida foi determinante. Da mesma forma, o paradigma pós-colonial da "World Dance" contribui com o entendimento de que todas as danças são potentes artisticamente, independente de sua origem étnica. 
Buscamos, por meio da assimilação da poética de uma artista consagrado da dança contemporânea, potencializar a dança do ventre como matriz para uma criação em dança. Participando das aulas da artista Eva Schul, compreendemos que sua poética possibilita a inclusão de diferentes matrizes de movimento, pois segundo Eva: "qualquer um pode dançar, desde que saiba usar seu repertório de movimentos e transformar o cotidiano em dança" [...] Sua técnica busca desenvolver um corpo natural, orgânico, expressivo, livre de tensões desnecessárias e apto à criação de um diálogo direto com o público" (DANTAS, 2013).

Porto Alegre tem uma história consolidada de dança contemporânea, da qual Eva Schul é uma figura importante. Em Nova York, foi aluna de Hanya Holm e Alwin Nikolais por 10 anos, tendo participado de aulas com Merce Chuningham e de cursos na Judson Church. Em 1974 Eva Schul inaugura em Porto Alegre o Espaço Mudança que tornou-se uma referência em dança contemporânea. Assim, também foi nosso interesse aproximar a dança do ventre da produção coreográfica contemporânea de Porto Alegre.

Diferente do trabalho de Cherkaoui em Puz/zle, onde os bailarinos mantinham suas técnicas e as exploravam para compor a temática híbrida do espetáculo, buscamos incorporar uma nova técnica pela assimilação no corpo e, desta forma, a noção de antropofagia na dança pareceu-nos um caminho para alcançar a hibridação desejada. Sobre a hibridação em dança Laurence Louppe afirma que:

\section{[...] todas essas misturas são ilusórias na medida em que o corpo do bailarino não for tocado. Como se sabe, não basta articular um gesto emprestado da dança indiana ou da dança barroca, ou com- binar uma corporeidade neoclássica com as desestabilizações à la Limón (como por exemplo, no trabalho de Forsythe), para que um discurso coreográfico se torne mestiço. Sabemos que este último não se limita apenas à enunciação formal de um "vocabulário" ges- tual, mas inclui uma filosofia de corpo, um trabalho sobre o tônus corporal, etc. É todo o dispositivo qualitativo do bailarino, tudo o que o constitui em sua relação com o mundo que deveria, na ver- dade, ser objeto de mutações e de misturas. (LOUPPE, 2000, p.28)}

Pensar a antropofagia como meio para a hibridação pelo corpo aproximou-nos das aulas de Eva Schul desejando que sua técnica fosse assimilada e incorporada, confundindo-se em meu corpo ${ }^{3}$ enquanto intérprete-criadora a fim de desestabilizar a matriz de movimento consolidada em mim por mais de 15 anos de prática ininterrupta de dança do ventre. Do encontro com a poética de Eva Schul destacamos dois aspectos que deram rumo a busca nas experimentações durante os ensaios: a ten-
3.

Andréa Soares foi intérprete-criadora da coreografia enquanto mestranda do Programa de Pós Graduação da UFRGS e Mônica Dantas foi orientadora do trabalho. 
dência por uso de movimentos com fluxo livre e o desenvolvimento da coreografia a partir de uma ou mais ideias.

As ideias trabalhadas em El Charque estiveram relacionadas a algumas recusas: recusamos conceber a dança do ventre como uma expressão cultural a ser preservada, recusamos a imutabilidade de sua forma tradicional de composição ${ }^{4}$ bem como o estereótipo da bailarina como um objeto sensual passivo. Assim, El Charque é uma ironia à busca por autenticidade egípcia na dança do ventre brasileira. Raqia Hassan, famosa professora egípcia da atualidade, distingue o Raks el Shark como sendo a legítima dança egípcia, enquanto belly dance seria uma criação norte-americana não reconhecida como "autêntica". O "Charque" é uma "apologia" à carne salgada gaúcha, assim chamada, e uma brincadeira com a palavra egípcia "Shark" seguindo o modelo de ironia antropofágica de Oswald de Andrade.

Em El Charque, os movimentos foram criados sem música, um repertório de ações foi apresentado em uma composição abstrata, mas capaz de levar o espectador à múltiplos sentidos. As ondulações dos braços, típicas da dança do ventre, foram enfatizadas e ressignificadas através de suas repetições. Outros momentos desenvolvidos na composição foram o quadril que se movia mesmo quando se tentava evitar e a transformação do característico movimento shimmy 5 , em uma ação que se realizava enquanto se empurrava uma parede imaginária.

Do choque à transversalidade: ver com olhos livres

A potência de explorar um material técnico clássico só foi possível devido à abertura que a poética da artista Eva Schul é capaz de potencializar. Utilizando sua poética, foi possível criar novos movimentos sem afastar-nos dos princípios filosóficos e éticos que são parte do ideal deste projeto artístico.

Acreditamos que assim como o oriente é muito mais complexo do que o descrito pelo orientalismo (SAID, 2007), as representações do feminino também tem sua complexidade que não podem resumir-se a objeto sensual. Desta forma, acompanhar a complexidade desta feminilidade é fator primordial para tornar a dança do ventre uma obra atual. Carregar o corpo da mulher de sentido é também carregá-lo de valor simbólico, valor moral, valor intelectual e isto nos serve tanto quanto filosofia de vida quanto potencial criativo.

Outro princípio filosófico que os estudos pós-coloniais nos ensinam é o princípio de igualdade entre as danças do mundo. Hoje, o hibridismo nas obras contemporâneas é uma constante e, muitas vezes, não é possível identificar a estética de uma obra de uma maneira simples e objetiva. Se por um lado
4.

A maneira tradicional de composição chama-se Oriental Routine ou Oriental Clássico e pressupõe uma forma preconcebida de interpretar a música árabe) 5.

Shimmy é um tremor percebido no quadril mas desenvolvido a partir dos joelhos. 
isto torna amplo o campo criativo, também pressupõe um pensamento aberto no sentido de "ver com olhos livres" todo o material que as danças ditas "exóticas" ou "primitivas" ou "populares" possam agregar às artes cênicas. É preciso abrir a mente para as culturas subjugadas e explorá-las como material de estudo e uma carne a ser consumida para alimentar estéticas híbridas e revitalizar a dança contemporânea.

Se o choque com o novo é inevitável, que seja aproveitado da melhor maneira para que um novo olhar - transversal permita novas concepções para a dança enquanto arte. Toda a matriz de movimento clássica pode ser carne para saciar a fome antropofágica de artistas contemporâneos que tenham a virtude de "ver com olhos livres" a potência desta mistura. 


\section{REFERÊNCIAS BIBLIOGRÁFICAS}

BHABHA, Homi. O local da cultura. 2. ed. Belo Horizonte: UFMG, 2010.

CANCLINI, Nestor Garcia. Culturas híbridas: estratégias para entrar e sair da modernidade. 4. Ed - São Paulo: Ed. da USP, 2011. CHERKAOUI, Sidi Larbi. Libreto do CD. In: Sidi Larbi Cherkaoui's Puz/le: A Filetta, Fadia Tomb El-Hage, Kazunari Abe, Olga Wojciechoswska. Austria: Eastman, 2013. 1 CD

DANTAS, Mônica. Corpos em trânsito / corpos antropofágicos: criação coreográfica e construção de corpos dançantes em Marché aux Puces. In: NORA, Sigrid (org.). Húmus 4. Caxias do Sul: Lorigraf, 2011. p. 13-21.

DANTAS, Mônica. Eva Schul: uma vida para reinventar a dança moderna e contemporânea. In: SÃO PAULO. SECRETARIA DE CULTURA. Figuras da Dança: Eva Schul.. São Paulo: Governo do Estado de SP, 2013.

FOSTER, Susan. Worlding dance: studies in international performance.Basingstoke; New York: Palgrave MacMillan, 2009.

KATZ, Helena. Larbi Cherkaoui, estrela espantosa. O Estado de São Paulo, São Paulo, 25 de outubro de 2013. Caderno 2, C9. Disponível em: http://www.helenakatz.pro.br/midia/helenakatz 41382698774.pdf . Acesso em: 16 de março de 2014.

LARAIA, Roque. Cultura: um conceito antropológico. Rio de Janeiro: Zahar, 2001.

LOUPPE, Laurence. "Corpos Híbridos." In: ANTUTES, Arnaldo et al. Lições de dança 2. Rio de Janeiro: UniverCidade Editora, 2000. p. 27 - 40.

ORNELLAS, Manoelito de. Gaúchos e beduinos: a origem étnica e a fomação social do Rio Grande do Sul. Porto Alegre: Martins Livreiro, 1999.

SAID, Edward. Orientalismo: o Oriente como Invenção do Ocidente. 2.ed. São Paulo: Companhia das Letras, 2007.

SHAY, Anthony; SELLERS-YOUNG, Barbara. Orientalism, transnationalism \& harem fantasy. Costa Mesa, CA: Mazda Publishers, 2005. 